\title{
As representações sociais no campo educativo
}

\section{Social representation in the educative field}

\author{
MichelGilly* \\ Tradução de Serlei Maria Fischer Ranzi** \\ Maclóvia Correa da Silva****
}

\begin{abstract}
RESUMO
Com exceção de alguns trabalhos como aqueles de mollo $(1970,1986)$ ou SIANo, (1985), há ainda poucas pesquisas no domínio educativo onde as representações sociais ocupam um lugar central. Para explicar resultados obtidos sobre os fatos que não têm estatuto de representação social, os autores ou bem estudam certos aspectos certas manifestações, ou abordam apenas fatores ou determinantes subjacentes (com estatuto de variável intermediária). Assinalaremos então primeiramente a importância de recorrer a noção de representação social no campo que nos interessa. Extrairemos em seguida, alguns resultados empíricos dos estudos realizados que nos situam sucessivamente do ponto de vista das relações entre representações sociais e discursos sobre as instituições, representações sociais e relação pedagógica, representações sociais e significações das situações e aquisições.

Palavras-chave: Representações sociais, significações e aquisições, campo educativo.
\end{abstract}

* Texto original: GILLY, M. Les représentations sociales dans le champs educatif In: JODELET, D. (Org.). Les rerprésentations sociales. Paris: Presses Universitaire, 1989.

** Doutora em História, Professora da Área Temática de História e Historiografia da Educação do Programa de Pós-graduação em Educação da Universidade Federal do Paraná. ranzi@netpar.com.br

*** Doutora em Planejamento Urbano, Professora do Programa de Pós-graduação em Tecnologia do Centro Federal de Educação Tecnológica do Paraná-CEFET/PR. mcsilva@ppgte.cefetpr.br 


\begin{abstract}
MOLLO (1970, 1986) or SIANO (1985), in which social representation are focused. Or the authors talk aboutsome aspects or manifestations, or they just treat about some factors or subjacentdeterminers (with a statute of intermediary variation) to explain obtained results that do not have statute of social representation. Right in the beginning of this article we will show up the importance of social representation in the field that we are interested. Hereafter we will extract some empiric results from other researches that situate us successively in the point of view of the relations among social representations and pedagogic relations, social representations, meaning of situations and aquisition.
\end{abstract}

Key-words: social representations, meanings and acquisitions, educative field.

\title{
O interesse de estudo das representações sociais no campo educativo
}

O interesse essencial da noção de representação social para a compreensão de fatos da educação é que ela orienta a atenção sobre o papel de conjuntos organizados de significações sociais no processo educativo. Assim como assinala DESCHAMPS et al. (1982), ela oferece uma nova via para a explicação de mecanismos pelos quais os fatores propriamente sociais agem sobre o processo educativo e influenciam os resultados deles; e da mesma forma, ela favorece as articulações entre psicosociologia e sociologia da educação.

Essa articulação diz respeito somente à compreensão de fenômenos "macroscópicos": as relações entre o pertencimento à um grupo social dado e as atitudes e comportamentos face à escola, a maneira como o professor concebe o seu papel etc. Ela diz respeito também aos níveis de análise mais sutis relativos à comunicação pedagógica no seio da classe e à construção de saberes.

Além do interesse desses estudiosos pela educação, os trabalhos no campo educativo trazem uma contribuição ao estudo das questões mais gerais que dizem respeito à construção e às funções das representações sociais. A partir da importância das tramas sociais que lhe são vinculados, o sistema escolar tem sempre, mais ou menos, como objeto de exemplos extraídos de grupos sociais ocupando posições diferentes em relação a: discursos de políticos e de administradores, discursos de agentes institucionais nos diferentes 
níveis da hierarquia, discursos de usuários. Mesmo se alguns desses traços são insuficientes e fragmentados, o campo educativo aparece como um campo privilegiado para ver como se constróem, evoluem e se transformam as representações sociais no seio de grupos sociais, e nos esclarecer sobre o papel dessas construções nas relações desses grupos com o objeto de sua representação. Compreendemos então por que os sistemas de representações são feitos de contradições. Com efeito, essas contradições se articulam nas totalidades coerentes em torno de esquemas dominantes que conferem às representações sociais níveis funcionais de adaptações segundo os níveis de realidade, aos quais são confrontados os sujeitos. As representações sociais garantem assim a estes últimos, a possibilidade de preservar seu próprio equilíbrio e sua própria necessidade de coerência no exercício de suas práticas sociais e no entorno de suas relações. Tudo isso é perceptível tanto numa perspectiva diacrônica, pela retomada de esquemas dominantes em momentos diferentes da evolução da escola, quanto numa perspectiva sincrônica, pela análise dos elementos contraditórios do discurso, em um dado momento, e o estudo de sua organização em torno de significações dominantes justificadoras das práticas.

\section{Discurso sobre a instituição e representações sociais}

As diferentes partes envolvidas (administradores, agentes centrais de decisão do sistema e usuários) incumbem uma importância crucial à reprovação escolar e às desigualdades sociais, face à escola, e esses indicadores estão entre os melhores reveladores dos aspectos centrais das representações que sustentam os diferentes discursos sobre a escola. O período recente é particularmente interessante uma vez que ele foi marcado, como assinalam PROST (1968) e DESCHAMPS et al. (1982), pela mudança mais importante surgida desde o início do ensino obrigatório na França. Sob a pressão das necessidades econômicas e sociais aconteceu de início, após a Segunda Guerra Mundial, a "explosão escolar"(CROs,1961) com a inflação dos efetivos e o rápido desenvolvimento das instalações; e em seguida, a partir dos anos 60, ocorreu o movimento de "democratização dos estudos" implicando a instalação de um aparelho institucional novo, embasado sobre o duplo princípio do prolongamento dos estudos, e do acesso ao ensino secundário aberto a todos. 
É ilustrativo então vermos como, segundo suas posições em relação à escola, os diferentes grupos enumerados a seguir elaboraram os sistemas de representações; ver como as contradições aferidas à escola foram tratadas, e como as representações sociais operaram compromissos de adaptação sob a dupla pressão, de um lado, das ideologias e de outro lado das pressões ligadas às finalidades e às condições efetivas de funcionamento do sistema escolar.

Não dispomos de pesquisas acumuladas concernentes a longos períodos de tempo, mas somente de alguns indícios a partir de análises sociológicas, psicosociológicas ou históricas. Entretanto, os referidos dados serão suficientes para mostramos que a representação não é uma imagem-reflexo da realidade escolar, de suas efetivas funções sociais e sim uma construção original visando legitimá-los. Com essa finalidade, a representação vai tanto mobilizar as posições ideológicas quanto procurar os apoios e as garantias científicas, em particular no domínio das ciências humanas e sociais.

\section{O discurso da escola sobre ela mesma}

Desde a sua origem a escola obrigatória está marcada por uma contradição profunda: de um lado o discurso ideológico igualitário, que vê na instauração do direito à instrução para todos, sobre os bancos de uma mesma escola, um meio de suprimir as distinções de classes; ${ }^{1}$ por outro lado, um funcionamento desigual que se traduz pelas diferenças de aprovação ligadas às diferenças sociais e a existência de redes escolares distintas para as crianças do povo e aquelas dos meios sociais abastados. Na sequiência, as desigualdades sociais face à escola vão, ao gosto das modificações de estrutura, tomar formas diversas, mas elas não cessarão jamais de existir (BAUDELOT; ESTABLET, 1971; MOLLO, 1986).

Como tratar essa contradição fundamental, inaceitável para um espírito humanista, se não for por uma construção representativa que permita legitimar o funcionamento desigual sem que sejam colocadas em causa o sistema e a ideologia igualitária. Com as evoluções ao longo dos tempos, iremos nos apoiar então sobre as supostas aquisições das ciências humanas, notadamente

1 Ver discursos de J. FERRY analisado por PROST (1986) e os comentários de DESCHAMPS (1982). 
da psicologia. A escola poderá ser declarada igualitária, oferecendo as mesmas chances para todos, explicando as desigualdades sociais de aprovação pelas diferenças atribuídas às crianças, desvantagens intelectuais, diferenças de "dons" e de "talentos". Nessa visão, as crianças dos meios desfavorecidos não reprovam por razões sociais, mas por que elas são, em média, menos dotadas do que as outras (BOURDIEU; PASSERON, 1964). E se elas vão para o ensino profissional de curta duração, é por que elas têm uma inteligência "concreta". Explica-se a reprovação e a seleção pelas "teorias do sujeito" e encontra-se, no discurso científico dos psicólogos, os argumentos (as diferenças de inteligência e de talentos estão ligadas às diferenças de categorias sociais) para garantir a representação proposta. $\mathrm{O}$ recurso à explicação pelo dom permite articular em um sistema coerente o discurso igualitário sobre a escola e o funcionamento desigual dela. A construção representativa funciona com o um estatuto de conhecimento que conforta a representação do senso comum (DESChAMPs et al.,1982). Ela dá boa consciência ao sistema sem que sejam questionadas as suas estruturas fundamentais e o seu funcionamento geral. Ela é sedutora também para os agentes da escola. Ela assegura uma função conservadora que protege suas práticas e remete para fora do aparelho escolar a explicação de suas vicissitudes.

Todavia, duas ordens de fatos virão modificar brutalmente as coisas: de um lado a evolução das posições científicas e por outro lado, as transformações estruturais do aparelho de produção e do mundo do trabalho. Os biólogos (ver RAMUZ, 1974; JACQUARD, 1982) afirmam que, no domínio do sistema nervoso superior, não há determinismo genético absoluto. Eles assinalam a influência da função sobre a estrutura no curso da maturação. Para eles, o papel do meio ambiente e dos seus estímulos é, neste caso, determinante. No que lhes concerne, psicólogos e sociólogos colocam também em causa a "ideologia do dom" em benefício da tese das "limitações socioculturais" (BERNSTEIN, 1961). Ao mesmo tempo, as necessidades de instrução e formação se intensificam e se diversificam sob a pressão do desenvolvimento das novas tecnologias e do setor terciário: o aparelho escolar é então levado à modificações. Entramos na segunda fase chamada: "democratização do ensino".

Esses dois tipos de fatores vão produzir as modificações que nos interessam no sistema representativo. O discurso oficial vai recusar cada vez mais a idéia de uma hierarquização dos indivíduos fundamentada nas suas diferenças. As crianças devem ser aceitas como elas são, na sua diversidade, e o objetivo da escola deve ser o de as desabrochar, quer dizer, de as educar apoiando-se sobre suas próprias potencialidades e respeitando sua singularidade. Nessa visão atual da escola, as orientações não vão mais se fundamentar 
sobre as desigualdades de "dons" ou de "talentos", mas se efetuar dentro do respeito as diferenças: esta é a "pedagogia do desabrochar"(DESCHAMPS et al., 1982; Mollo, 1986). De um outro ponto de vista, se as crianças de diferentes meios sociais não são iguais diante da escola igualitária, isto não é porque aquelas, de meios desfavorecidos são menos "dotadas" do que as outras, mas porque elas são deficientes pelas privações e pelas carências culturais do seu meio. $\mathrm{O}$ discurso científico da desvantagem cultural (mesmo que ele seja levemente criticado pelos pesquisadores) é prontamente integrado. Sua influência, ligada à influência de fatores econômicos e sociais, terá por consequiência uma regressão do ensino especial segregativo, em proveito de uma política de integração de deficientes e de ações sociopedagógicas compensatórias nas escolas de locais desfavorecidos. Mas, no fundo do problema nada mudou radicalmente: os benefícios dessas ações são pequenos, as crianças de meios desfavorecidos continuam de qualquer forma a reprovar e a ter percursos escolares diferentes dos outros, conduzindo-as para as profissões socialmente pouco valorizadas (MOLLo, 1986); além disso, a norma escolar a partir da qual se opera a diferenciação de classes sociais por escola é sempre aquela da cultura dominante. O sistema de representação articula em um todo coerente as contradições entre ideologia e realidade, e assegura sempre sua função de legitimação do sistema e de justificação de práticas.

Acabamos de pincelar em grandes traços dois esquemas centrais dominantes, em dois momentos da história da instituição. Seria necessário detalhá-los mais e mostrar que o tema do "despertar" estava presente há muito tempo, sob a influência de ideologias progressistas, mas a título secundário, na representação que a escola dá a ela mesma; mostrar também que a "ideologia do dom" e dos talentos natos deixa seqüelas no modelo do "despertar", mesmo se à idéia de dom se substitui parcialmente a idéia de "mérito" (LONDEIX, 1982). Poderemos citar, a título de exemplo, as análises muito refinadas que faz MOLLo (1986) a propósito do primeiro ciclo do secundário durante a década que seguiu a instauração da prolongação do ensino. O que é preciso reter, de essencial, é que o sistema escolar se transforma sob a pressão de dificuldades econômicas e sociais que fixam os critérios de sua rentabilidade. A representação, sistema simbólico de mediação, segue essas mudanças. Ela traz em si elementos contraditórios dos quais alguns antecipam as evoluções possíveis. Mas foi necessário que o sistema escolar fosse empurrado por determinantes externo para que a construção representativa oficial começasse a oscilar e a se reorganizar em torno de um novo esquema central, legitimado pelos empréstimos às ciências humanas e sociais, e legitimando por sua vez o funcionamento do sistema. 


\section{O discurso de agentes da instituição}

a) A escola fundamental vista pelos inspetores.

O estudo de voluZan (1975) merece uma atenção particular. Por um lado porque ele se apoia em uma amostra importante de textos analisados com critérios lingüísticos rigorosos. Por outro lado, ele coloca em cena uma personagem na articulação entre a administração escolar, que dita as normas, e a realidade cotidiana do funcionamento das aulas que ela está encarregado de controlar. Este estudo nos introduz de imediato no centro das representações: através das seleções realizadas sobre o que é descrito do funcionamento das aulas e os "julgamentos" e "conselhos" explicitados.

Duas coisas então impressionam. Primeiro, a complexidade do sistema de representações considerado, uma vez que o discurso nos remete a muitas imagens, cada uma muito diversificada, da infância, do aluno, dos objetivos de mudanças pela educação, das relações mestre-aluno e do professortipificado. Mas também pelo fato que, a despeito dessa complexidade, contradições descobertas tecem elos entre os diferentes elementos. Emerge uma estrutura de conjunto dominante que toma forma de transposição, ao nível do funcionamento da aula, da estrutura hierárquica institucional e das relações de dependência que regem as relações hierárquicas entre agentes do sistema. É em torno dessa estrutura dominante, a propósito da qual voLUZAN cita o modelo "tradicional", que se organiza o essencial do discurso. Poderemos consultar voluZAN (1975) para a descrição impactante que ela nos dá dele. (notadamente p. 67 e p. 112-129). Grosso modo, nós somos levados novamente a uma imagem do funcionamento da escola e da sala de aula marcada pela corrente filosófica tradicional das pedagogias da essência (SUCHODOLSKI, 1960) e a concepção que lhes é mais freqüentemente associada de uma infância imperfeita a ser modelada pela imposição de uma relação mestre-aluno fundamentalmente dissimétrica; o que não é incompatível com uma certa visão humanista que diz respeito ao homem a ser construído e a ingerência da afetividade no modelo, que este último recupera, de uma outra forma, com conotações moralizantes judaico-cristãs do dom próprio da criança e da sabedoria de ser agradável ao adulto. Além disso, notaremos, que ao privilegiar o rendimento a serviço dos objetivos coletivos padronizados, os valores da cultura dominante, amoldando a criança em benefício do aluno, (elemento despersonalizado da entidade-classe) o modelo proposto somente pode perpetuar as desigualdades ligadas ao status social. 
Ainda que se organizando em torno deste modelo dominante, a representação comporta também, ao contrário, os elementos constitutivos de um modelo marcado, ao mesmo tempo, pela corrente filosófica das "pedagogias da essência" (sUCHODOLSKI, 1960) e a influência contemporânea das ciências humanas e sociais: respeito a maneira de ser da criança, estabelecimento de uma comunicação horizontal com o mestre, personalização da pedagogia com apoio sobre os trabalhos, iniciativas e experiências pessoais dos alunos e o levar em conta o grupo e suas comunicações internas. Nesse modelo, a função do mestre mudou; ele organiza, guia, segue os ritmos individuais, mas não impõe. voluZAN fala do "modelo adaptativo" visando o "desabrochar", o desenvolvimento da colaboração, da cooperação e da iniciativa.

Destacamos então, como anteriormente, a presença de aspectos contraditórios. Mesmo assim, a representação afirma sua função de coerência dando um estatuto central aos elementos que confortam a inércia de um modo de funcionamento experimentado, que dá segurança, mantém os hábitos, protege das vertigens da mudança, deixa-se ancorar sobre um modelo passadista, que os mesmos indivíduos criticariam, certamente, se eles tivessem consciência de que o modelo sustem no essencial os seus enunciados em um de seus principais atos profissionais. Os elementos que anunciam uma evolução possível estão contudo sob efeito de raízes antigas. Mas eles são secundários, ou recuperados. Sobre esse assunto, vOLUZAN retoma muito bem, por exemplo, a ambigüidade da referência à atividade dos alunos, muito presente no modelo dominante, mas recuperada sob forma do "aluno tendo agido " e não do aluno tendo a iniciativa da ação.

b) A escola e seu funcionamento vistos pelos professores de ensino fundamental.

Encontra-se, num estudo mais recente de MEYER (1978-1981), o mesmo dualismo subjacente quando os professores falam de suas práticas. Mas é sempre o modelo "tradicional" que predomina na estruturação de sua representação. Isso nos leva a pensar que, a despeito das orientações do discurso oficial, as reformas institucionais sucessivas advindas desde o recolhimento dos dados de voluZAN (terminados em 1969), não têm, ou ainda não, provocado mudanças suficientes das finalidades sociais do aparelho escolar e das práticas para que o sistema de representação dos profissionais seja obrigado a se reorganizar em torno de um outro modelo dominante.

As análises recentes de MOLlo (1986) a partir de entrevistas com os professores do CM2 confirmam inteiramente esta hipótese. Os profissionais 
entrevistados, no momento mesmo da supressão des filiéres ${ }^{2}$ do sexto ano, conservam uma visão diferencial do sistema. Eles não são vítimas do discurso igualitário oficial (o que não os impede de utilizá-lo junto aos pais, mas como um discurso retransmitido). A experiência deles o convence da persistência de uma realidade seletiva. Para eles as aparências mudaram, mas a função permanece sob outras formas. É a força dessa crença que explica o pouco engajamento dos professores ao tratar a informação disponível sobre a reforma e a ignorância constatada pelo autor. Isso depende da construção esquematizante e reducionista de toda representação, daí advindo tomadas fragmentárias e engajadas assinaladas por mollo. Somente aquilo que é compatível com o esquema central é pesquisado e incorporado na informação. Esse esquema opera uma associação plena de potencialidade, retomada também pelo autor, entre a idéia da manutenção de uma função implícita seletiva e a importância associada ao nível dos alunos. Confrontados com o cotidiano, os professores não podem aderir à idéia de diferenças não hierarquizadas entre crianças, que fundamenta o modelo oficial do "despertar" (cf. p. 366-369), pois essa idéia é incompatível com a visão que eles têm da manutenção de uma função diferencial da escola. A despeito da instauração de uma estrutura unificada de acolhimento, há ainda, para eles, alunos "fortes" e "fracos" condenados a percursos escolares desiguais. E é sempre em referência ao modelo hierárquico que eles organizam o essencial de sua prática. Quão surpreendente então para o autor que as referências aos "dons" e qualidades intrínsecas aos alunos permanecem muito presentes no seu discurso, e que os protótipos do bom e do mau aluno sejam muito semelhantes (MOLLo fala da rigidez ) há aqueles recuperados, mais de 10 anos antes (MOLLO, 1970), em outra população de professores! A única diferença sensível é a referência tornada freqüente no meio familiar para explicar as dificuldades na escola. MARC (1984) fez também uma constatação do mesmo tipo. Podemos ver nela os efeitos da tese da desvantagem cultural (cf. p. 366-369). Esse elemento novo é facilmente integrado no sistema de representação já que não é suficiente reconsiderálo na sua dupla função defensiva e justificativa das práticas.

2 Des filières trata-se de um ensino específico em vista de uma orientação profissional definida. 


\section{Os pais falam da escola}

Sabemos, há muito tempo, que as famílias, segundo sua origem social, não têm os mesmos comportamentos face à escola. Partindo dos dados de uma sondagem sociológica, realizada em 1963, CLERC (1970) constatava que as desigualdades de orientação, no final da escola primária entre crianças de meios sociais diferentes, não podiam ser explicadas unicamente pelas diferenças de aprovação escolar, uma vez que existiam variações importantes de orientação persistiam na igualdade de aprovação. Ele estimava que as desigualdades de comportamento interferiam, separadamente, quase da mesma forma nas desigualdades de aprovação quando se explicava diferenças de orientação.

As diferenças de comportamento tomam formas diversas nos diferentes níveis de escolaridade e evoluem ao mesmo tempo que evolui o sistema escolar; mas elas estão sempre presentes. Podemos explicá-las, em parte, e os sociólogos não deixaram de fazê-lo, pelos fatores financeiros (custo dos estudos etc.) e geográficos (implantação de estabelecimentos escolares). Mas esses fatores não são suficientes. E isso nós vimos bem em BOURDIEU e PASSERON (1964) propondo o conceito de "esperança subjetiva". Esse conceito está na interseção da abordagem sociológica e da abordagem psicosociológica. Ele chama a atenção do psicólogo a respeito do que representa a escola para os familiares de diferentes meios sociais, as relações entre suas representações e seus comportamentos e as conseqüências decorrentes deles a propósito das representações e comportamentos de crianças.

Nos dois estudos tendo como interesse as representações (ZOBERMAN, 1972; PAILLARD; GILLY, 1972), os autores constataram que, comparadas as famílias de meio socialmente favorecidos com as famílias de meio social desfavorecidos, aquelas davam, em média, mais importância às funções escolares tradicionais de instrução (saberes de base) do que às funções mais amplas de formação cognitiva (abertura e cultura do espírito) e de formação sociorrelacional. Além disso, o estudo de PAILLARD e GILly mostrava que as famílias de meios sociais desfavorecidos esperavam da escola que ela assegurasse claramente e rapidamente a sua função de seleção para com os diferentes tipos de "filiéres" e que elas retomassem por sua conta a ideologia do dom para explicar as dificuldades escolares das crianças de seu próprio meio. Em média, o discurso delas traduzia igualmente a presença de atitudes menos críticas e mais conformistas com respeito à escola do que aqueles familiares de meios mais favorecidos. Paradoxalmente, ao menos em aparência, sua 
privação cultural as conduzia então a valorizar os saberes escolares sobre os quais a escola se apoia mais na sua função seletiva, ao encontro de suas próprias crianças. $\mathrm{O}$ acesso a esses saberes escolares, dos quais elas se sentiam diminuídas, representa para elas, ao mesmo tempo, uma possibilidade de reabilitação social e cultural do seu grupo e a esperança bem concreta que, graças à escola, suas crianças poderiam pretender uma melhor inserção socioprofissional que a delas. A fascinação do modelo cultural dominante, através do qual o seu grupo aspira à uma mudança de identidade, as tornava pouco críticas com respeito às finalidades e ao funcionamento da escola. Simultaneamente, sua adesão à ideologia do dom, e à crença na inferioridade das crianças de seu grupo, as conduzia a querer estar estabilizadas relativamente rápido no futuro, daí o desejo realista delas de que a escola assegure claramente sua função de avaliação-orientação.

Em um trabalho recente junto a pequenos camponeses, SIANO (1985) nota igualmente que eles têm, no conjunto, uma atitude pouco crítica com respeito à escola e que eles esperam dela que ela assegure sua função seletiva. Isso ocorre ainda que a população pesquisada pertença a um grupo profissional ameaçado pelas mutações tecnológicas e transformações da economia agrícola. Essa ameaça torna-os sujeitos muito sensíveis à questão escolar: é graças aos saberes ensinados na escola que eles pensam que suas crianças poderão perpetuar a exploração familiar, transformar os modos de exploração e de gestão do capital terra, ou então se reciclar em um outro tipo de atividade profissional. Mas tudo se passa como se a importância do desafio tornasse mais sutil ainda as contradições do sistema de representações. SIANO fala, com respeito a essas contradições, de "consciências paralelas" permitindo, por exemplo, fazer coexistir uma reivindicação de igualdade e de justiça social, e a realidade desigual da escola; ou ainda, de fazer coexistir a ligação do valor ancestral do trabalho manual, associado ao desejo de uma escola que não produz intelectuais em excesso e a desconsideração do mesmo trabalho manual associada, desta vez, ao desejo de ascensão pela escola.

SIANO se propõe a explicar algumas dessas contradições pela persistência de elementos profundamente ancorados na história das mentalidades camponesas. Mas se os elementos desse tipo persistem, é exatamente porque eles têm valor adaptativo. Diante das dificuldades escolares efetivas das crianças de seu grupo e as incertezas de uma promoção pelo saber escolar, os pequenos camponeses da sondagem alimentam crenças que permitem aceitar o veredito seletivo da escola. Isto não quer dizer que eles permaneceram insensíveis às evoluções de certas idéias. Por exemplo, é impressionante constatar que as propostas da quase totalidade dos casos veiculam um modelo 
interacionista apresentado mais freqüentemente com muita complexidade: as chances de aprovação são vistas como dependentes simultaneamente da criança, do meio familiar e do meio escolar. Mas no quadro desta visão modernista, seu interacionismo não é construtivista: a escola, da mesma forma que o meio familiar, não pode dar à criança o que ela não tem. Em última análise, é o valor individual da criança que é julgado determinante; a ideologia dos dons e a ideologia meritocrática continuam a ocupar um lugar central. Face às desigualdades diante da escola, a importância das condições ambientais, extrínsecas é reconhecida (os efetivos das salas de aula, formação dos mestres, possibilidades materiais e culturais das famílias etc.), mas a última palavra retoma as qualidades intrínsecas da criança: suas capacidades e seu mérito. A esse nível, as modulações ligadas aos pertencimentos ideológicos-sindicais dos pais, da pesquisa, se apagam. Temos ali um elemento central muito duro que persiste no sistema geral das representações dos pequenos camponeses e que conduz SIANO a falar de representações sociais "auto-seletivas" e "alienantes", na medida em que elas lhes permitem aceitar a reprovação de suas crianças e a função seletiva da escola.

\section{Representações sociais; relações pedagógicas e aquisições}

A priori, pode não parecer evidente que uma noção tão ampla quanto esta das representações sociais, que remete à sistemas complexos de significações elaborados por grupos sociais, tenha a ver com as práticas pedagógicas (in vivo). É que o discurso científico sobre a pedagogia nos tem habituado, sem dúvida, a explicações exclusivamente procedimentais (ou mecânicas) fundamentadas sobre modelos locais de funcionamentos e de mecanismos ligados às características intrínsecas dos sujeitos (funcionamento cognitivo, ritmo biológico dos alunos, etc.; competências técnicas, qualidade relacionais dos professores etc.), ou ainda sobre os modelos técnicos de aprendizagem (métodos, programação de cursos etc.). A visão científica relativamente recente da sala de aula como um sistema social interativo, cujo funcionamento deve ser compreendido por referência à um ambiente social mais amplo, orienta um certo número de correntes de trabalhos em direção às abordagens que ocupam um amplo espaço nas significações ajustadas a situações pedagógicas para compreender o que se passa na escola. 
Disso resultam articulações com as representações sociais, seja porque elas aparecem diretamente relacionadas, seja porque as significações levadas em conta mantêm relações estreitas com elas.

\section{Apreensão do aluno pelo mestre; protótipos de escolares e ação pedagógica}

a) Sistema de apreensão e percepção do aluno singular

O conjunto dos trabalhos efetuados, a partir de julgamentos de professores sobre os alunos, colabora para evidenciar o impacto determinante das funções atribuídas nos registros sobre as dimensões que sustentam o sistema geral de apreensão a partir do qual cada aluno singular é percebido (para uma revisão da questão, cf. GILLY, 1980, p. 57-80). Isso observamos do maternal ao ensino secundário. Tudo passa como se o sistema de apreensão estivesse sustentado por duas dimensões principais das quais se extraem sua significação das normas que definem o papel: objetivos e modalidades de funcionamento. As análises fatoriais disponibilizam sempre um primeiro fator comum importante (30 a $60 \%$ da variação total segundo os estudos) de impressão geral interpretável com relação à função de "instrução". Isto traduz a existência de um forte sincretismo de julgamentos instruído, em primeiro lugar, por valores de atitude face ao trabalho (mobilização, participação e motivação) e em segundo lugar, somente pelos valores cognitivos, os aspectos convergentes do pensamento (qualidade de assimilação) prevalecem sobre os aspectos divergentes (qualidades criativas). Muito concretamente quanto mais o aluno tende a ser percebido sob um aspecto favorável do ponto de vista desses valores fortemente desejados a nível socioinstitucional, tanto mais ele tende a ser percebido favoravelmente para todo um conjunto de outras características, incluídas aquelas como beleza, a força física etc. $\mathrm{O}$ segundo fator extraído abarca, conforme os estudos recenseados de 14 a $21 \%$ da variação total. Ele é interpretável com relação à função de gestão da sala de aula, e coloca a ênfase sobre a conformidade às regras sociais e morais da vida escolar (relações com o mestre e entre as crianças), permitindo o funcionamento do grupo favorável à aquisição dos saberes propostos em um contexto pedagógico diretivo e hierárquico habitual. 
Foi mostrado que a dimensão sincrética da apreensão está bem ligada à satisfação profissional experimentada pelo professor em relação à aprovação escolar dos alunos (GILLY, 1972) e que os dois fatores descritos têm uma grande estabilidade: eles são pouco influenciados pelo sexo dos professores, o sexo dos alunos, o nível de escolaridade e a maior parte das ideologias de referência estudadas (GILLY, 1974, 1980). Os únicos efeitos sensíveis observados, referentes à significação e ao peso dos fatores, aconteceram no caso em que as diferenças de ideologias pedagógicas acompanhavam as diferenças nítidas das práticas e no caso de comparações entre profissionais da educação que exerciam funções nitidamente diferentes (GILLY, 1980, p. 101-103). Mais uma vez, confirmamos a influência preponderante das práticas efetivas sobre os fatos de representação no papel que o agente desempenha. É evidente a relação entre as dimensões do sistema de apreensão do aluno pelo mestre, no seio da sala de aula, e os elementos mais gerais de sua representação social da escola, evocada anteriormente. É assim porque a sua representação do sistema escolar privilegia o modelo dominante de rendimento para atingir os objetivos coletivos, onde a criança perde sua identidade em proveito do elemento entidade-classe e é visto numa relação de dependência hierárquica fundamentada sobre a imposição diretiva do mestre, em que o professor percebe cada aluno singular a partir de um modelo de apreensão caracterizado pelas duas principais dimensões assinaladas.

A influência subjacente das representações sociais sobre a apreensão dos alunos somente tem efeito sobre o sistema de apreensão descrito acima. Os trabalhos realizados por solARI $(1972,1981)$ mostram que a apreensão se observa também a propósito da seleção das atividades escolares e dos índices de situação de onde o professor tira suas informações para a construção de cada imagem do aluno. Poderemos nos referir também a GILLY (1980, p. 118121; GILLY, 1986) para os detalhes sobre este assunto. Lembremos que comparando somente os julgamentos trazidos pelos mestres da escola maternal sobre os seus alunos e as observações precisas dos comportamentos dos mesmos alunos em duas atividades com valorações escolares diferentes, sOLARI constatou que os julgamentos dos professores não mantiveram relações com os índices comportamentais observados na atividade com a mais forte valorização escolar (iniciação à escrita); e também, que os professores se apoiaram mais sobre índices comportamentais, com forte valor expressivo, sem que estes índices tivessem necessariamente valor funcional do ponto de vista da mobilização necessária para a tarefa. Encontramos, neste caso, a influência do sistema geral de representações que, ao privilegiar um certo modelo de aluno, conduz ao duplo fenômeno bem conhecido de seleção e de interpretação dos índices informativos na apreensão de cada aluno singular. 
b) Sistemas de apreensão e protótipos de alunos.

Com os "protótipos" tirados da análise das respostas dos professores sobre os comportamentos dos seus alunos, nós passamos de um universo dimensional (em termos de fatores) a um universo tipológico (em termos de tipos de alunos). weIss (1986) assinala as semelhanças entre os quatro tipos descritos pelos professores nos seus próprios trabalhos (weIss , 1984) e aqueles de LONDEIX (1982), e as relações entre estes protótipos e as categorias de comportamentos extraídas das análises fatoriais de KAUFMANN (1976) e GILLY (1980). Estes protótipos são os seguintes: dois para os bons alunos, julgados pelos professores aptos a continuar os estudos (o aluno ativo, sociável e inteligente; o aluno aplicado e disciplinado); dois para os maus alunos, julgados inaptos a continuarem os estudos (o aluno passivo, repetente e pouco dotado; o aluno pouco trabalhador, disperso e indisciplinado) (weIss, 1986).

Percebemos como esses quatro protótipos poderiam ser situados por referência aos eixos fatoriais anteriormente definidos e as relações que eles mantêm com os aspectos gerais da representação da escola. É isso que assinala LONDEIX (1982) quando levanta a hipótese que cada tipo de bom aluno remete à uma concepção dada de escola: o bom aluno, ao mesmo tempo inteligente dinâmico, que fala bem e com sociabilidade agradável, seria mais freqüentemente do meio social favorecido e evocaria o modelo ainda vivo da escola de "elites" fundamentada sobre a ideologia do dom e do brilho. O aluno aplicado, disciplinado, perseverante e conscencioso seria de preferência o protótipo do bom aluno dos meios sociais culturalmente pouco favorecidos remetendo à uma concepção de escola "meritocrática" (ver igualmente os comentários de wEISs, 1986, p. 93-98).

c) Meio social, apreensão do aluno pelo mestre e relação pedagógica.

Outros fatos, além daqueles evocados anteriormente, testemunham as relações existentes entre origem social dos alunos e representações do professor sobre o seu sujeito, e com respeito a seu destino escolar. MARC (1984) observa as diferenças na atribuição das causas da reprovação escolar dos alunos da escola primária. Para este autor, as causas invocadas pelos professores de sua sondagem, no caso de crianças de operárias imigrantes, correspondem à representação do aluno "preguiçoso", “contestador", "responsável” pela sua reprovação, enquanto que no caso das crianças do setor terciário, as causas invocadas correspondem à representação do aluno, cuja lentidão é "corrigível" e as dificuldades "perdoáveis". DEGOUYs et al. (1985) notaram igualmente diferenças, no início do secundário: com aprovação idêntica, os alunos, em 
média, não percebiam que os professores não adotavam a mesma postura em relação à matemática e que os professores não atribuíam mais aos mesmos fatores as possibilidades de aprovação futura.

Muitos autores, entre eles MARC (1984), retomam a idéia de que essas diferenças de representação do professor podem contribuir de forma importante para explicar as diferenças de aprovação. A expectativa pessimista, decorrente de uma representação desfavorável das famílias de meio desfavorecido, de sua relação na escola e das atitudes escolares de suas crianças, poderiam ser a origem de atitudes e comportamentos relacionais do pedagogo, em boa parte responsáveis pelos maus resultados previstos. A explicação proposta é aquela do efeito pigmalião (ROSENTHAL e JACOBSON, 1968).

Nós chamamos a atenção para a prudência com a qual convém considerar esse modo de explicação e criticar o modelo de implicação causal que o caracteriza (GILLY, 1980). As diferenças sociais produzem realmente efeitos sobre a forma pela qual o professor apreende e explica os problemas dos alunos. Sem falar que essas diferenças não significam sempre desvantagem para as crianças de meios desfavorecidos (GILLY; FARIOLI, 1976), uma vez que o tratamento dado pelo professor depende de todo um conjunto de condições que deve ser considerado de forma mais nuançada e complexa do que sugere o modelo linear do efeito pigmalião.

É isso que mostram muito bem as observações in vivo de Roux (1980, 1981) e PERRENOUD (1982). As diferenças ligadas aos meios sociais conduzem efetivamente os professores observados a uma desigualdade de tratamento pedagógico, mas essa desigualdade de tratamento apresenta contradições. Os dois autores notam que ela tem uma visão compensatória para um "investimento didático ou relacional mais apoiado junto aos menos favorecidos" (PERRENOUD, 1982, p. 115); mas ao mesmo tempo, sob algumas de suas formas, "ela ativa a desigualdade das aprendizagens e favorece à sua maneira os mais favorecidos" (Ibid., p. 116). A prática está a mercê da vontade igualitária. Mas muitas das interações permanecem, ainda assim, "seletivas" e "a face positiva (da diferenciação) que poderia beneficiar os desfavorecidos não é a medida das diferenças entre os alunos" (Ibid., p. 125). A pedagogia compensatória a bel-prazer não escapa do caráter contraditório das representações que a sustenta. Considerando as condições de funcionamento e os objetivos efetivos do sistema escolar (no qual o professor não tem o curso universitário completo), sem levar em conta tentativas compensatórias reais, então o risco é grande que seja este o modelo dominante do rendimento e do protótipo do aluno correspondente, prevalecendo mais freqüentemente na orientação dos comportamentos diferenciais com os alunos. 


\section{Representações sociais; significação de situações escolares e construção de saberes}

Só iremos evocar rapidamente, para terminar, um certo número de orientações atuais de pesquisa onde o lugar designado para as significações das situações, das tarefas dos interlocutores convida à articulações úteis com o estudo das representações sociais propriamente ditas. É o caso dos trabalhos como aqueles de BROSSARD $(1981,1982)$ que dizem respeito às significações associadas pelo aluno às situações escolares e atividades que até ali são praticadas. A arte de ler (BROSSARD, 1981) para o aluno de diferentes níveis de significação (a curto, médio e longo prazo) das aprendizagens propostas é evidentemente tributária dos sistemas mais gerais de representação da escola, e de suas finalidades que caracterizam os diferentes meios sociais familiares. Uma outra articulação se impõe a propósito das noções de "contrato de comunicação" e de "contrato didático" utilizadas pelos autores (ELBERS, 1986; GROSSEN, 1986; SCHUBAUER-LEONI, 1986) que estudam, as representações que as crianças têm das situações de comunicação com o adulto - quer dizer do seu papel, de suas expectativas a seu respeito, do sentido de suas intervenções - estas representações determinam a maneira pela qual elas concebem seu próprio papel e se comportam do ponto de vista cognitivo. Por sua vez, um certo número de trabalhos (CHEVAlLARD, 1980; CONNE, 1981; e sobretudo PERRET-CLERMONT et al.,1981) chama nossa atenção sobre o interesse da noção de representação social a propósito dos próprios conteúdos de conhecimentos a aprender. PERRETCLERMONT et al., (1981) insistem sobre os fenômenos de "descontextualização" e "recontextualização" sucessivos do saber a cada etapa de sua transmissão social (do saber acadêmico ao saber proposto para a criança) por processos de seleção e de reorganização da informação. As práticas sociais sucessivas (seleção dos conteúdos de ensino, construção dos manuais, preparação do ensino pelo pedagogo) operam a cada vez reconstruções de um objeto novo, de representações sociais sucessivas do saber científico inicial finalizados pelos objetivos das mesmas práticas sociais consideradas. A questão se complica mais ainda caso se queira considerar que, os alunos não alcançam a maior parte desses objetos de ensino com a mente vazia de todo conteúdo, mas com um conjunto de representações "iniciais" ou "ingênuas" (BOMBI, 1981; SÉRÉ, 1985; WEIL-BARAIS, 1984) enraizadas nas suas crenças, usos e práticas de seus próprios meios de vida o que nos remete de novo à questões subjacentes de representações sociais. Uma última arti- 
culação interessante pode ser feita, enfim, com os trabalhos que estudam, sobre a etiqueta de "estigma social", como a referência experimental da criança, com normas e usos que regem as práticas sociais, podem favorecer certas aprendizagens cognitivas (DOISE e MUGNY, 1981; MUGNY e DOISE, 1983; GIROTTO, 1987; GILly e ROUX, 1988; ROuX e GILly, 1984; ZHOU, 1987). Essa articulação é largamente tratada em outras obras. (ver o capítulo de DOISE).

\section{Observações finais}

Algumas pesquisas mencionadas na segunda seção (cf. p. 365-375 - "Discurso sobre a instituição e as representações sociais") mostram o interesse que poderiam apresentar os estudos sistemáticos e renovados junto das diferentes categorias de populações consideradas pela escola. Os trabalhos citados nos mostraram que as representações sociais, enquanto sistemas autônomos de significações sociais, são de fato o fruto de compromissos contraditórios sob a dupla pressão de fatores ideológicos e de pressões ligadas ao funcionamento efetivo do sistema escolar; o peso dessas últimas parece tão forte quanto os indivíduos estão diretamente relacionados ou implicados nas práticas cotidianas. Vimos então que, diante de uma instituição que está longe de realizar de fato as mudanças esperadas, os indivíduos se apoiam, para guiar e justificar seus comportamentos, sob os sistemas representacionais os quais privilegiam mais freqüentemente elementos e esquemas de forte inércia.

Para que as representações se transformem profundamente, pelas reorganizações em torno de outros elementos e esquemas centrais, presentes nas representações atuais, todavia dominados, seria necessário, provavelmente que as mudanças sociais induzissem mudanças funcionais mais radicais da instituição e das práticas profissionais. Mas talvez fosse necessário também, para que desaparecesse toda referência à idéia de hierarquia e desigualdades diante da escola, que as inserções no mundo do trabalho, as quais se apoiam necessariamente sobre as diferenças de percurso e de perfis escolares, não repousassem mais elas próprias sobre o modelo hierárquico "prestígio social-poder-dinheiro" que marca a representação social do mundo do trabalho. Isso quer dizer que os sistemas de representações sociais relativos à escola não podem ser considerados independentemente de seus laços com outros sistemas gerais de representações sociais dos quais eles são dependentes. 
Mas, nós vimos também que o estudo das representações sociais não apresenta um outro interesse que não seja aquele voltado para si. As perspectivas de pesquisa relatadas no terceiro item (cf. p. 375-382 - "Representações sociais; relações pedagógicas e aquisições") nos mostraram que o que se leva em conta nos grandes sistemas organizados de significações que os constituem é útil também para a compreensão daquilo que se passa na sala de aula da interação educativa propriamente dita, tanto do ponto de vista de objetos do saber ensinados, quanto dos mecanismos psicossociais, por vezes muito sutis para o trabalho nas aprendizagens.

Não seria necessário para tanto fazer das representações sociais uma panacéia universal. Para a psicossociologia o recurso a esse contexto teórico não pode, no campo educativo, ser substituído por todo um conjunto de modelos locais - ver sobre esse caso o recenseamento de ARNAULT DE LA MÉNARDIÈRE; MONTMOLLIN (1985) a propósito notadamente de conceitos de "protótipo", "esquema", "script" - cujo valor heurístico provém de sua adequação aos objetos de estudo bem delimitados. Mas ele permite ampliar nossa compreensão dos fatos estudados realocando-os nos campos mais vastos de significações sociais dos quais eles são dependentes.

\section{REFERÊNCIAS}

BEAUDELOT, E. R. L'ecole capitaliste en France. Paris: Maspero, 1971.

BERNSTEIN, B. Social structure, language and learning. Educanional Research, n. 3, p. 163-176, 1961.

BOMBI, A. S. The development of the child's conception about economic. Colloque du laboratoire européen de Psycologie sociales et champ éducatif, Aix en Provence, 1981.

BOURDIEU P.; PASSERON, J. C. Les héritiers. Paris: Les Editions de Minuit, 1964.

BROSSARD, M. Situation et signification: approche des situations scolaires d'interlocution. Revue de Phonétique appliquée, n. 57, p. 13-20, 1981.

. Na approach to scholl interlocution situations: analysis of a few examples. In: LOWENTHAL; VANDAMME; CORDIER (Ed.). Language anda language acquisition. New York: Plenum Press, 1982. p. 243-254. 
CHARLOT, B.; FIGEAT, M. L'école aux anchères. Paris: Payot, 1979.

CHEVALLARD, Y. Mathematiques, langage, enseignement: la réforme des années soixante. Recherches, n. 42, p. 71-79, 1980.

CLERC, P. La famille et l'orientation scolaire au niveau de la sixième. Population et l'enseignement, Paris, p. 143-188, 1970.

CONNE, F. La transpositio didactique à travers l'enseignement des mathématiques en première e deuxième année de l'école primaire. Genève, 1981. Thèse (Doctorat) Faculté de Psycologie et des Sciences de l'Education, l'Université de Genève.

CROS, L. L'explosion scolaire. Paris: Cuip, 1961.

DEGOU YS, J.; GRAS, R.; POSTIC, M. Attitude à l'égard des mathématiques des élèves de sixième. Revue internationale de Psycologie appliquée, n. 34, p. 53-82, 1985.

DESCHAMPS, J. C.; LORENZI-CIOLDI, F.; MAYER, G. L'échec scolaire. Elèvemodèle ou modèles d'élèves? Lausanne: Pierre-Marcel Favre, 1982.

DOISE,W.; MUGNY,G. Le developpement social de l'intelligence. Paris: Intereditions, 1981.

ELBERS, E. Interaction and instruction in the consevation experimen. European Journal of Psycology of Education, n. 1, p. 77-89, 1986.

GILLY, M. La représentation de l'élève par le maitre à l'école primaire: cohérence entre aspects structuraux et différentiels. Cahiers de Psycologie, n.15, p. 201-205, 1972.

GILLY, M. La représentation de l'élève par à l'école primaire: aspectos liés au sexe de l'élève e au sexe de enseignant. Psycologie Française, n. 19, p. 127-150, 1974.

GILLY, M. Psycosociologie de l'education. In: MOSCOVICI, S. (Ed.). Psychologie sociale. Paris: PUF, 1984. p. 473-494.

GILLY, M.; FARIOLI, F. Milieu socio-familiar, statut scolaire et représentation de l'élève par le maitre à l'école primaire. Psychologie française, n. 21, p. 159,173, 1988.

GILLY, M.; ROUX, J. P. Social marking in ordering tasks, Effects and mechanisms. European Journal of Social Psichology, n.17, p. 251-266, 1988.

GIROTTO, V. Social marking, socio-cognitive conflict and cognitive Development. European Journal of Social Psichology, n. 17, p. 171-186, 1987.

GROSSEN, M. Interaction adulte-enfant dans une situation de test: présentation d'une recherche en cours. Cahiers de Psycologie de l'Université de Neuchâtel, n. 24, p. 15$22,1986$. 
JACQUARD, A. Au péril de la science? Paris: Le Seuil, 1982.

KAUFMANN, J. P. La perception des élèves par des enseignants: comparaison des résultatas fournis par deux méthodes d'analyse. Bulletin de Psycologie, n. 30, p. 3045, 1976/1977.

LONDEIX, H. Structure factorielle de l'opinion des professeurs sur leurs élèves. L'orientation scolaire et professionnelle, n. 11, p. 169-190, 1982.

MARC, P. Autour de la notion pédagogique d'attente. Berne: Peter Lang, 1984.

MEYER, R. Statut de la sanction et image de l'enfant dans la représentation de l'enseignant à l'école élémentaire. Aix-en Provence, 1978. Thése (3e cycle) - Université de Provence, 1978.

MEYER, R. Une approche de l'image de l'enfant chez les enseignants de l'école élémentaire. Bulletin de Psycologie, n. 35, p. 213-220, 1981.

MOLLO, S. L'école dans la société: psycosociologie des modèles éducatifs. Paris: Dunod, 1970.

MUGNY, G.; DOISE, W. Le marquage social dans le développement cognitif. Cahiers de Psycologie cognitive, n. 3, p. 89-106, 1983.

PERRENOUD, P. H. De l'inégalité pédagogique devant le système d'enseignement, L'action pédagogique et la différence. Revue européenne, des sciences sociales, n. 20, p. 87-142, 1982.

PERRENOUD, P. H. La fabrication de l'excellence scolaire: du curriculum aux pratiques d'évaluation, Genève-Paris: Droz, 1984.

PERRENOUD, P. H. L'évatuation codifiée et le jeu des règles: aspects d'une sociologie des pratiques. In: KETELE, J. M. de. (Ed.). L'evaluation: approche descriptive ou prescriptive ? Bruxelles: De BockWesmael, 1986. p.11-29.

PERRET-CLERMONT, A. N. et al. Décontextualisation et recontextualisation du savoir dans l'enseignement des mathématiques à de jeunes élèves. Interactions didactiques. Recherches, n.1, p. 1-33, 1982.

PROST, A. L'enseignement en France, 1800-1967. Paris: Armand Colin, 1968.

RAMUZ, M. Biologie et éducation. In: GFEN (Ed.). L'échec scolaire: doué ou non doué? Paris: Editions Sociales, 1974. p. 117-123.

ROSENTHAL, R.; JACOBSON, L. Pygmalion in the classcoom: teacher expectation and pupils'intellectual development. New York: Rinehart \& Winston, 1968.

ROUX, J. P. Réussie scolaire et interactions yadiques maîtresse-élève. Aix-enProvence, 1980. Thèse ( $3^{\circ}$ cycle) - Université de Provence, 1980. 
ROUX, J. P. Les interventions des maîtresse en grande section maternelle. Bulletin de Psycologie, n. 35, p. 52-66, 1981.

ROUX, J. P.; GILLY, M. Aide apportée par le marquage social dans une procédure de résolution chez des enfants de 12-13 ans: données et réflexions sur les mécanismes. Bulletin de psycologie, n. 38, p. 145-155, 1984.

SCHUBAUER-LEONI, M. L. Le contrat didactique: un cadre interpré-tatif pour comprendre les savoirs manifestés par les élèves en mathématiques. European journal of psycologie of education, v. 1, n. 2, p.139-153, 1986.

SÉRÉ, M. G. Analyse des conceptions de l'état gazeux qu'on les enfants de 11 à 13 ans, en liasion avec la notion de pression, et proposition de stratégies pédagogiques pour en faciliter l'évolution. Paris, 1985. Thèse (d'État), Université de Paris.

SIANO, V. L'école, la société et les payasans, Représentations sociales, idéoligies et mentalités: étude d'une opulation de petits agriculteurs du Vaucluse. Aix-enProvence, 1985. Thèse (Doctorat de $3^{\circ}$ cycle), Université de Provence.

SOLARI, M. J. La mobilisation de l'enfant à l'âge de la maternelle: mise au point d'une technique, premiers résultats. Cahiers de Psycologie, n. 15, p. 159-169, 1972.

SOLARI, M. J. Les fluctuations temporelles et comportementales de la mobilisation en grande section maternelle, et leur incidence sur la représentation de l'élève par la maêtresse. Bulletin de Psycologie, n. 35, p. 67-87, 1981.

SUCHODOLSKI, B. La pédagogie et les grands courants philosophiques. Paris: Editions du Scarabée, 1960.

VOLUZAN, J. L'école primaire jugée. Paris: Larousse, 1975.

WEIL-BARAIS, A. L'étude des connasissances des élèves comme préalable à l'action didactique. Bulletin de Psycologie, n. 38, p. 157-160, 1984.

WEISS, J. La subjectivité blanchie. In: KETELE, J. M. (Ed.). L'évaluation; approche descriptive ou prospective? Bruxelles: De Boeck-Wesmael, 1986.

ZHOU, R.M. Marquage social, conduites de partage et construction de la notion de conservation chez des enfants de 5-6 ans. Aix-en-Provence, 1987. Thèse (Doctorat) Université de Provence, 1987.

ZOBERMAN, N. Attentes des parents vis-à-vis de l'école maternelle. Cahiers de Psycologie, n. 15, p. 239-246, 1972.

Texto recebido em 15 dez. 2001

Texto aprovado em 15 abr. 2002 